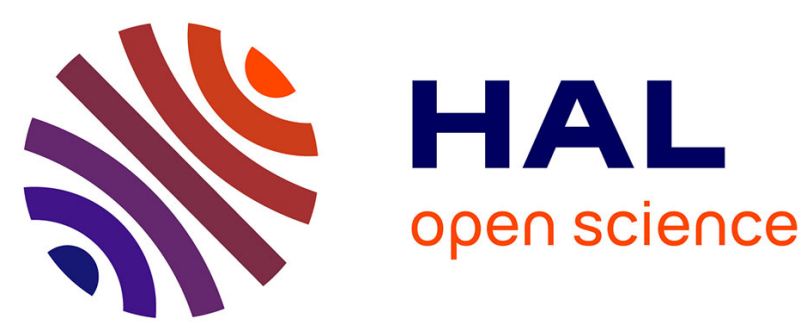

\title{
Framework to Model PSS Collaborative Value Networks and Assess Uncertainty of Their Economic Models
}

\author{
Xavier Boucher, Khaled Medini, Camilo Murillo Coba
}

\section{To cite this version:}

Xavier Boucher, Khaled Medini, Camilo Murillo Coba. Framework to Model PSS Collaborative Value Networks and Assess Uncertainty of Their Economic Models. 20th Working Conference on Virtual Enterprises (PRO-VE), Sep 2019, Turin, Italy. pp.541-551, 10.1007/978-3-030-28464-0_47 . emse02290372

HAL Id: emse-02290372

https://hal-emse.ccsd.cnrs.fr/emse-02290372

Submitted on 14 Feb 2020

HAL is a multi-disciplinary open access archive for the deposit and dissemination of scientific research documents, whether they are published or not. The documents may come from teaching and research institutions in France or abroad, or from public or private research centers.
L'archive ouverte pluridisciplinaire HAL, est destinée au dépôt et à la diffusion de documents scientifiques de niveau recherche, publiés ou non, émanant des établissements d'enseignement et de recherche français ou étrangers, des laboratoires publics ou privés. 


\title{
Framework to Model PSS Collaborative Value Networks and Assess Uncertainty of their Economic Models
}

\author{
Xavier Boucher, Khaled Medini and Camilo Murillo Coba \\ Mines Saint-Etienne, Université Clermont Auvergne, CNRS, UMR 6158 LIMOS-Institut \\ Fayol, 158 Cours Fauriel, F-42023 Saint-Etienne, France \\ e.l.m. leblanc SAS, Bosch-Thermotechnology, 126 rue de Stalingrad, F-93 705 Drancy \\ cedex, France \\ $\{$ xavier.boucher, khaled.medini, camilo.murillocoba\}@ mines-stetienne.fr
}

\begin{abstract}
This paper presents a framework for addressing the challenge of economic value sharing among actors of Product-Service value networks. More specifically the framework is dedicated to the assessment of alternative collaborative value networks and their associated economic models, at the time of designing a product-service system (PSS). The framework includes three main components: modelling, simulation and uncertainty assessment. The framework is briefly presented as parts of its components were discussed in previous research. The paper provides an illustration with a design project of a PSS solution in the agro-alimentary industry, requiring a balanced configuration of collaborative value network
\end{abstract}

Keywords: Product Service Systems, Value network, Economic models.

\section{Introduction}

Innovation on Product-Service-Systems generated a rather large background of scientific advances on supporting their design and engineering processes over the last decade. However, their concrete operationalization remains confronted to key challenges, notably concerning the balance of multi-actor collaboration within PSS value chains. The mix among products and services open new profit opportunities and, consequently, a strong need to regulate economic value sharing among collaborative actors. This paper tackles this challenge by proposing an integrated framework to assess economic models of PSS collaborative delivery networks. The framework is based on three key components: modelling, simulation and uncertainty assessment.

The paper is structured according to these three dimensions: modelling, simulation and uncertainty assessment of collaborative PSS value networks, with a state of the art (section 2) introducing these three aspects, a conceptual contribution highlighted in section 3 , and a case study in the agro-alimentary industry in section 4 . This case 
study puts forth a multi-actor value network, emphasizing the economic-sharing issues.

\section{Modelling and Evaluation of PSS Collaborative Value Networks}

\subsection{Modelling of PSS Value Networks}

Over the last decade, key advances were developed in the field of PSS Modelling [1] to support the integration of products and services models. This section is focused on papers about modelling PSS value network to support their economic assessment. A first set of models support an explicit representation of actor networks, which can be extended to stakeholders. The research works from [2] model the value flows of a PSS offer through a generic formalism of Receiver/Provider actors, using a mathematical representation. Lindahl goes one step forward by considering the various types of PSS network actors and establishing a qualitative approach to model the service-based or product-based value flows among them [3]. An approach where actor networks are represented through value creation scenarios is proposed in [4] and the sustainability of alternative value proposition scenarios is addressed in [5]. In these 2 last works, the final objective is a performance assessment, however the quantitative assessment process are not developed. This first set of works provide advances for qualitative modelling, but do not address economic evaluation.

Complementarily, in the field of strategic network analysis, stakeholder value network has been developed to assess value flows among stakeholders and identify dependency or power relationships [6]. Until now, this approach has not been applied specifically to PSS. In the field of PSS, the PRO-VA approach provides a seminal work for multidimensional value assessment [7]. The authors build a clear contribution to assess both monetary and non-monetary value. However the approach only focuses on the provider's point of view and on PSS components: it does not assess the value network in itself. This second set of modelling work provides important insights on value exchange assessment, however they do not make possible an explicit and sharable representation of alternative scenarios of collaborative value networks and do not analyse precisely the economic flows among actors.

\subsection{Simulation of PSS Value Networks}

Simulation methods offer quantitative assessment solutions, with a direct focus on value network modelling: based on process-oriented models, all activities required for PSS delivery are modelled and their integrated performance can be simulated. Typical of this orientation, is the work from Bosch-Mauchand et al. [number] using discrete simulation to assess value criteria in terms of cost, risk, product conformity, time and function satisfaction [8]. The authors compare value creation scenarios according to the point of view of the various actors of the network. However, this approach remains only product-oriented. In the field of PSS, some contributions conceptualize the basis for generic PSS simulation platform [9;10], by integrating both service and product dimensions. A service-oriented performance simulation method is developed 
in this general perspective in [11]. Simulation models for PSS business is proposed for specific application areas and decisional objectives in [12]. Such works provide concrete advances for quantitative evaluation, however the alternative value network models are not explicitly represented, and a domain-independent platform for PSS value network is still missing.

\subsection{PSS Uncertainty Analysis for PSS Economic Assessment}

Uncertainty management is a key issue for PSS design. In the field of PSS uncertainty propagation was applied to some PSS concrete cases [13; 14] for economic evaluation. An uncertainty diagnosis approach, integrating both qualitative and quantitative methods, was applied in the PSS context in [13; 15]. Wang and Durugbo [16] define a set of uncertainty metrics evaluated by applying fuzzy-based techniques. However, these advances on uncertainty in PSS context mainly focus on cost of service delivery and market conditions. Revenues or other dimensions of economic models are not considered. Additionally, current contributions mainly emphasize on the provider point of view, without considering all stakeholder's impacts.

\section{A Framework for PSS Value Network Modelling \& Evaluation}

The following sections present a modelling and assessment framework for PSS, as an integrated approach to tackle the key issues identified previously: (i) provide an explicit and sharable representation of the diversity of collaborative value networks at the time of PSS solution design; (ii) support a multi-actor simulation of PSS value network economic models; (iii) assess the impact of distinct types of uncertainties for various stakeholders. Three integrated components of the framework are introduced (Fig. 1): modelling, simulation, uncertainty assessment. PSS value networks are constituted by collaborative sets of companies contributing to PSS delivery, including PSS user when necessary. By hypothesis, the approach only deals with BtoB PSS context and the value network assessment only considers economic dimension of value exchanges. 


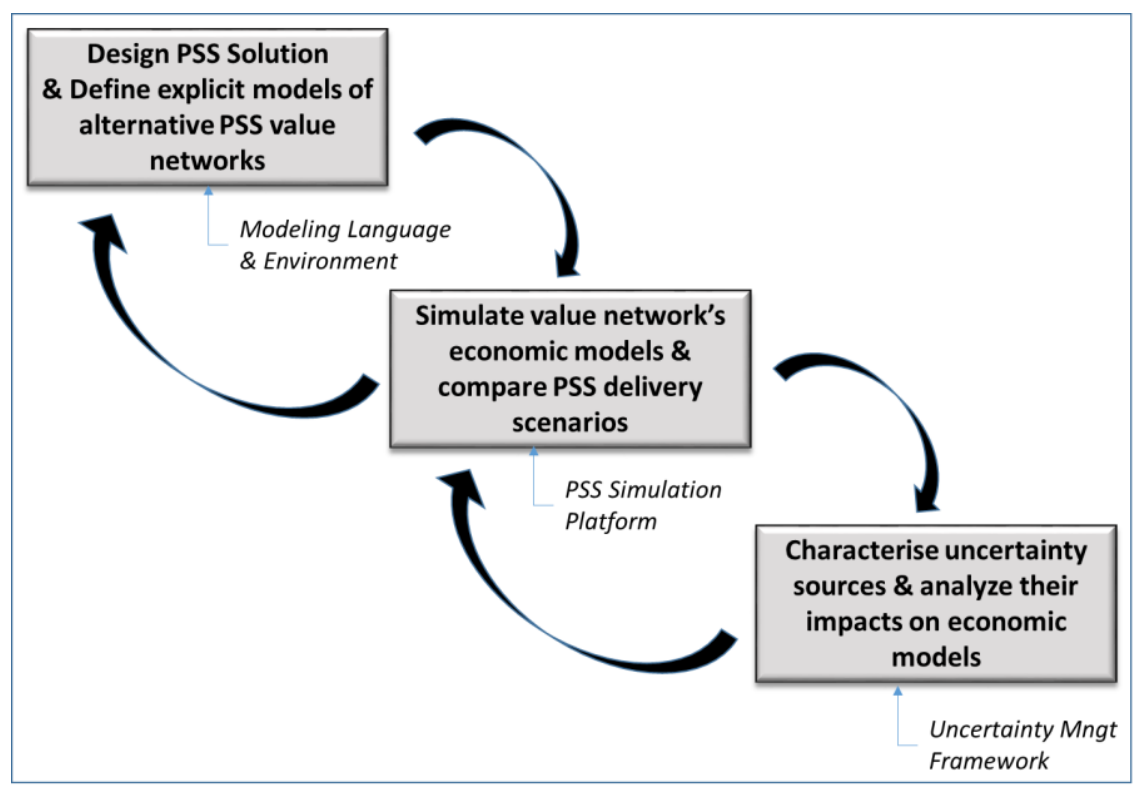

Fig. 1. Overview of the overall Framework

\subsection{A Modelling Language for Value Network Representation}

The modelling component was developed on a conceptual level as a modelling language dedicated to PSS models and, on a pragmatic level, as a computer-based modelling tool called PS3M (PSS Scenario Modeler). PS3M offers 9 complementary views to support PSS design process [17, 18]. The so-called 'Scenario view' is dedicated to model PSS collaborative value networks, using three major modelling constructs:

- PSS Offer: each alternative value network is associated to a specific Offer, including the specification of PSS components together with the characterization of PSS selling contract (The Offer view further details the precise elements of the offer).

- Actor Roles: each value network gathers a set of Roles, with the Role specifying the responsibilities and activities taken in charge by some actor of the value network. The delimitation of the roles is specific to each value network configuration. Performance indicators can also be associated to Roles, to characterize performance expectations.

- Organizational Actors represent the various companies/organizations involved in the value creation network. They can be assigned to the various Roles within the value network depending on their organizational capabilities and on the designer decisions.

With this three modelling concept several alternative value networks can be defined, each specified by a specific offer, a set of roles necessary to deliver all the components of this PSS offer and the assignment of organizational actors to these roles.

Figure 3 of the case study illustrates the graphical representation of the PS3M Scenario View. The modelling language presents the advantage of an explicit representation of the alternative options of collaborative value networks for PSS 
delivery, using a graphical representation easily understandable by any actor of the network, thus facilitating collaborative decision-making. Another important feature of PS3M modelling language also consists in supporting the identification of the characteristics and parameters of the economic models under study. This economic data is captured from the actors of the network, then gathered throughout the nine views of the modelling language, helping the subsequent step about economic model evaluation through simulation (see next section).

\subsection{Simulation Platform for PSS Collaborative Value Networks}

The simulation component has been developed as a reconfigurable PSS Economic model simulator called PS3A (PSS Scenario Analyzer). The objective of the platform is to make possible to generate a reliable cost/revenue simulation of the various alternative PSS delivery scenarios defined via the previous PS3M modelling component. The platform is consistent with a multi-actor perspective, by providing economic results (costs/revenues/profits) for each of the actors of the collaborative PSS delivery network.

The economic calculation model follows an activity cost/revenue assessment approach applied both to manufacturing and service processes, with the formalized model and algorithms detailed in [19]. The costs of each actor within the PSS network are the aggregate manufacturing and service activities assigned to each of those actors. Revenues are derived from the costs using manufacturing or service margin rates. The calculations are executed for a given demand profile representing the yearly number of contracts [19].

The platform is reconfigurable, in the sense that the internal economic calculations provided by the simulator are precisely customizable for each PSS case study. A technological interoperability between PS3M (modelling component) and PS3A (simulation component) was implemented in order to accelerate the customization of the simulation platform for each case study and ensure a higher level a reliability for the economic outputs generated.

\subsection{Uncertainty Propagation and Analysis Procedure}

The simulation platform ensures reliable economic outputs to compare alternative PSS value networks. However, managing uncertainty requires embedding the simulator within a consistent uncertainty management framework. As presented in [20], this Framework results from the integration of qualitative and quantitative methods for uncertainty analysis and management. It includes the four main steps underlined by figure 2: step 1 consists in defining, characterizing and classifying the potential sources of uncertainty; step 2 consists in formalizing a mathematical representation of uncertain parameters; step3 consists in propagating uncertainties through the PSS economic model calculator (presented in 3.2) using Monte Carlo simulations, to support a sensitivity analysis; step 4 consists in interpreting the outputs from this sensitivity analysis to look for action plan reducing uncertainty impacts (mitigation strategies). 


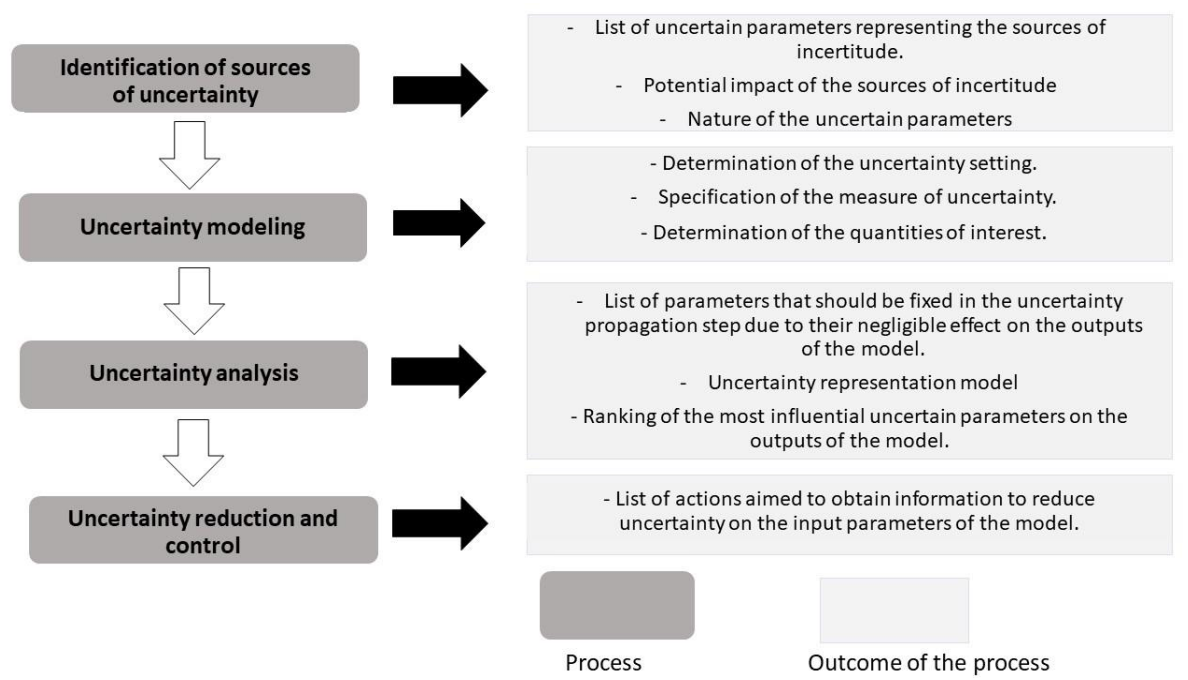

Fig.2. Overview of the uncertainty management process

\section{Case Study in the Field of Industrial Robotics}

The case study concerns the development of a PSS solution for the meat industry (agro-alimentary sector). The PSS offer envisioned offer is a robotic solution for easy cleaning of the fridges, where the meat undergoes the transformation process. The current cleaning activities interfere with the production, leading to higher cost and lower cleaning quality. The innovative offer entails an autonomous cleaning robot with specific moving and cleaning abilities dedicated to meat environment, and a set of services to ensure the availability and performance of the robot, reduce the production interferences and improve the cleaning frequency and quality. The PSS collaborative value network involves three stakeholders: (E1) a small-sized manufacturing company that designs and assembles special machines including robots as customized solutions, (E2) a small-sized manufacturing company that provides batteries for the robot and (E3) a medium-sized company from the meat transformation industry as the client of the offer. A fourth stakeholder (E4) is considered in some of the configurations: a service provider that assumes the role of PSS solution provider. The application of the framework helps configuring the collaboration among stakeholders, by supporting the design of alternative value chains and by the analysis of the potential economic results through the simulation and uncertainty approach, as presented in the next sections.

\subsection{Key Results Concerning PSS Value Network Modelling}

The PSS modelling language introduced in section 3.1, was implemented on the ADOXX enterprise modelling platform (open meta-modelling platform supported by the Open Models Laboratory initiative - OMiLAB). The resulting PS3M modelling 
environment (fig. 3) is utilized in order to build consistent models of the alternative PSS value networks, which are associated to distinct potential economic models.

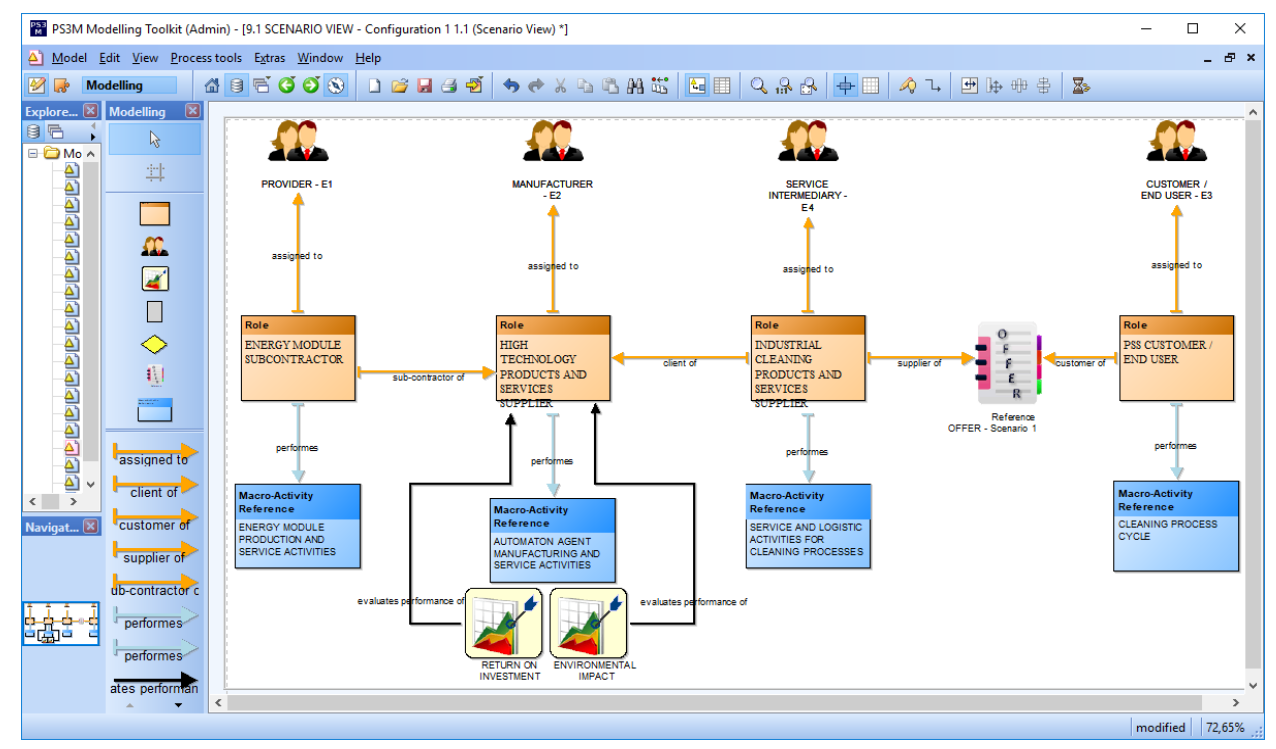

Fig. 3. Example of PSS value chain, modelled through PS3M modelling component

Typically, for the Clean Robot case study, the value network could be implemented following the usual product-, use- or result-oriented PSS economic models. The structure of the value network strongly depends on these economic schemes: the content of the 'offer', the roles in the value network and the organizational actors, considering their internal economic parameters. Figure 3 shows a PSS value network for a use-oriented contract offer with roles assigned to the 4 actors: the customer E3 takes in charge the cleaning activity, the service intermediary E4 manages the contractualization, the manufacturer E1 provides the robot and technology-oriented services, and the battery provider E 2 ensures specific maintenance tasks. Economic analysis discussed in next section only focuses on the three main alternative scenarios described in table 1 .

Table 1. Three alternative PSS scenarios, for further economic analysis

\begin{tabular}{l|l|l|l}
\hline Actors & S1 - Product oriented PSS & S2 - Use oriented PSS & S3 - Result oriented PSS \\
\hline E1 & $\begin{array}{l}\text { Sells the robot and services } \\
\text { to E3 }\end{array}$ & $\begin{array}{l}\text { Provides the robot and } \\
\text { services on an availability } \\
\text { basis }\end{array}$ & $\begin{array}{l}\text { Takes over the cleaning } \\
\text { of E3 fridges }\end{array}$ \\
\hline E2 & $\begin{array}{l}\text { Sells the battery system to } \\
\text { E1 }\end{array}$ & $\begin{array}{l}\text { Sells the battery system to } \\
\text { E1 }\end{array}$ & $\begin{array}{l}\text { Sells the battery system } \\
\text { to E1 }\end{array}$ \\
\hline E3 & $\begin{array}{l}\text { Purchase and use the robot } \\
\text { for cleaning the fridges }\end{array}$ & $\begin{array}{l}\text { Purchase and use the robot } \\
\text { for cleaning the fridges }\end{array}$ & $\begin{array}{l}\text { Pays for the cleaning } \\
\text { service }\end{array}$ \\
\hline
\end{tabular}




\subsection{Key Results Concerning PSS Economic Model Simulation}

The modelling presented in the previous section supported the definition of the required data for the simulation. This latter is performed following the algorithmic approach and the model presented in [19]. The simulation model is implemented in web-based platform allowing a quick modelling and simulation process. The output is a set of cost and revenue indicators for different actors involved in the designed offer. The simulations show a significant increase in E1 net profit when moving towards a more service-oriented offer (Fig. 4). Unsurprisingly, E2 profit remains stable over the three scenarios as it is only a supplier of the battery system. Scenario S2 referring to a use-oriented offer brings an additional revenue stream coming from the monthly rent of the robot and most importantly maintenance services. The net profit is doubled from S1 to S2. For the customer E3, this increase in costs is compensated by more availability of the equipment and thus better cleaning performance. E1 profit increase is more significant when it comes to the result-oriented scenario as the profit increases with almost $260 \%$ compared to S2. This is explained by the big share of cleaning service in the profit: this service is delivered by A1 in S3, instead of the customer in S2. From a mere economic point of view, this shows that the profit generated by delivering the cleaning process outranks the one from the initially designed PSS. However, in practice, this scenario is hindered by organisational issues linked to service capabilities of $\mathrm{E} 1$ and business competition of the cleaning market: the final decision regarding the most appropriate scenario belongs to the project consortium.

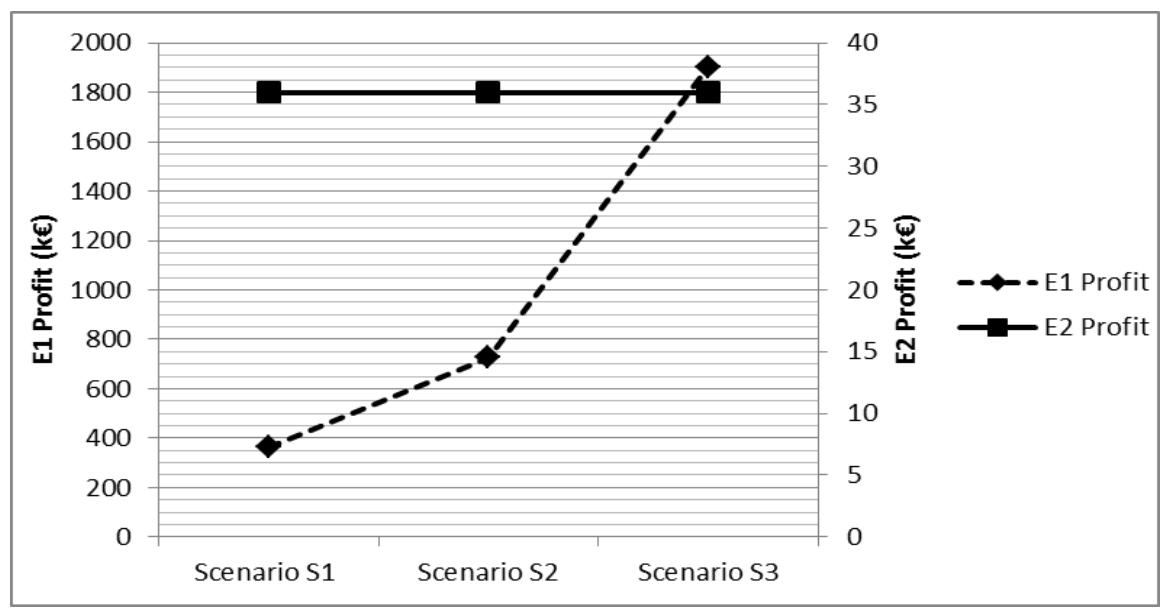

Fig. 4. Economic assessment results 


\subsection{Key Results Concerning Uncertainty Propagation and Analysis}

The goal in this stage is to identify the parameters of the economic model that have the largest influence on the variability of the profits for the actors of the value chain. These analyses were applied to the use-oriented scenario (S2), considered as the more interesting for the industrial actors.

First, a One-at-a Time (OAT) sensitivity analysis was performed on a set of parameters: contract length, number of contracts initiated each year, lease amount, robot lifetime, frequency of services, number of robots, robot payback period and contract type. Then, tornado diagrams were plotted to visualize the influence of these key parameters on the variability of the revenues for E1, the Original Equipment Manufacturer (OEM) (Fig. 5). A base scenario with a set of parameters was defined, and then two other scenarios with 'extreme' values were specified. Due to the large influence of the demand on the variability, three diagrams with different values of initiated contracts per year were plotted. The use of these tornado diagrams enabled to visualize the negligible impact on the variable of interest of varying the values of robot lifetime and frequency of services. This result led to the decision of not including these two parameters in the uncertainty propagation step.

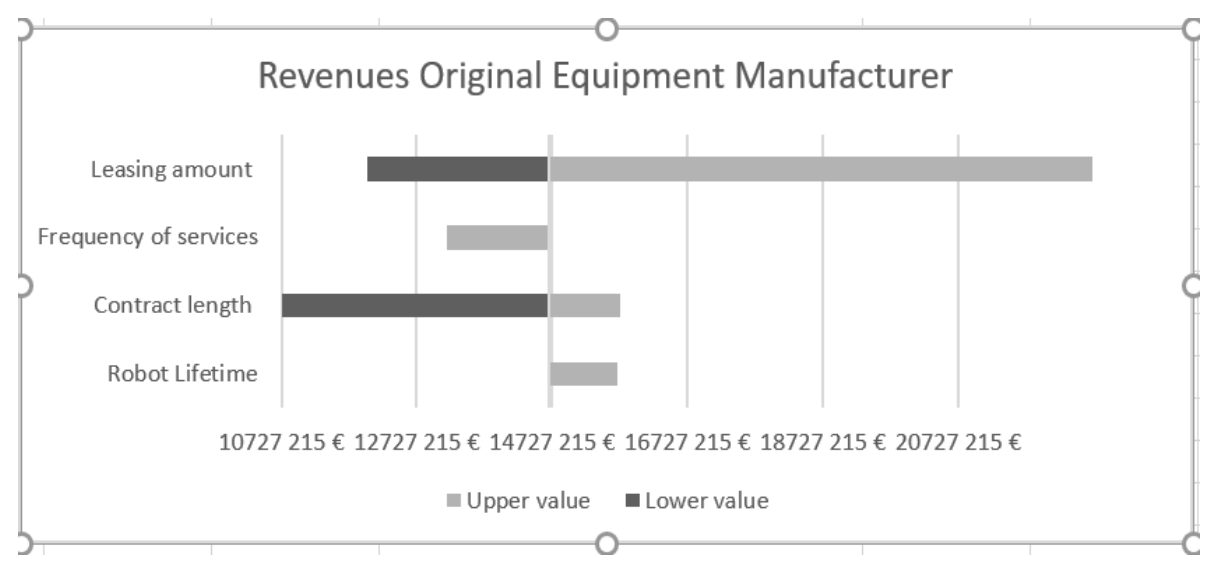

Fig. 5. Example of a tornado diagramme used in the uncertainty analysis

In order to include the effects of the interactions among uncertainty parameters, a scenario decomposition was applied, and then, the finite change sensitivity indices were calculated [20]. This sensitivity analysis set the parameters for the next step of uncertainty propagation step: another two parameters were considered to have a negligible effect on the simulated revenues: number of operating robots and robot payback period. Next, the economic model was run 1000 times while variating the values of the contract length, the number of contracts initiated per year, the lease amount and the robot lifetime.

The outputs of the simulations were analysed by using scatterplots and Pearson correlation coefficients (Fig. 6) [20]. Scatterplots assist in screening the degree of sensitivity between a parameter and the variable of interest. From the resulting 
scatterplots, it was concluded that the main parameter having high sensitivity to the simulated revenues for the OEM and the battery supplier was the number of ongoing contracts per year. This conclusion was drawn from the presence of a pattern in the chart. This finding was confirmed by the computation of the Pearson correlation coefficients. On the contrary, the remaining charts displayed points uniformly scattered; which indicated low sensitivity to the expected revenues (Fig. 6).

This analysis led to the conclusion that demand for robotic industrial cleaning solutions represented the largest uncertainty source in the economic model. The increasing variation of the lease amount and contract length showed to have also a positive effect on the profits, when Robot lifetime demonstrated to have a negligible effect.

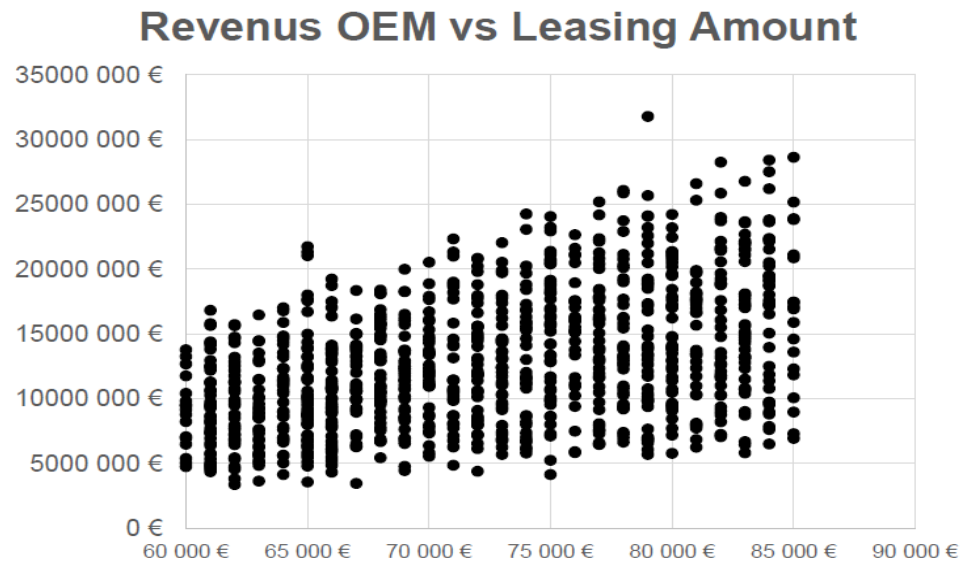

Fig. 6. Example of a scatterplot used in the uncertainty analysis

\section{Conclusions}

The industrial case study illustrates how the modelling, simulation and uncertainty components of the framework help industrial consortiums to identify and characterize, alternative economic models available to implement collaborative PSS delivery networks and, then, evaluate and confront them to uncertainty. Thus, the framework supports a decision-making process which, first, makes explicit alternative economic value sharing scenarios, second helps selecting the best scenarios by a comparative analysis of economic results, then assesses the sensibility of these results to uncertainty factors. An important perspective under development is the genericity of the approach, to cope with the variability of potential PSS economic models. 


\section{References}

1. Qu, M., Yu, S., Chen, D., Chu, J., Tian, B.: State-of-the-art of design, evaluation, and operation methodologies in PSS, Computers in Industry, 77, pp. 1-14, (2016).

2. Sakao, T., Sundin, E., Lindahl, M., Shimomura, Y.: A methodology for Designing Services: A modeling Method, Design Method, CAD Tool and thiuer industrial Applications, in Service Engineering, Salvendy, G. \& Karwowski , W., Edt J. Wiley \& Sons, pp. 269-293, (2010).

3. Lindahl, M., Sakao, T., Carlsson, E.: Actor's and System Maps for Integrated Product Service Offerings - Practical Experience from Two Companies. Procedia CIRP 16, pp. 320 $-325,(2016)$.

4. Medini, K., Moreau, V., Peillon, S., Boucher, X.: Transition to Product Service Systems: methodology based on scenarios identification, modelling and evaluation, Proceedings PROVE'2014, 6-8 October 2014 - Amsterdam, Netherlands, (2014).

5. Neubert, G., Lambey-Checchin, C.: The Sustainable value proposition of PSSs: the case of ECOBEL "Shower head", Procedia CIRP 47, pp.12 - 17, (2016).

6. Reed, M., Graves, A., Dandy, N., Posthumus, H.: Who's in and why? A typology of stakeholder analysis methods for natural resource management. J. Environ. 90, pp.19331949, (2009).

7. Matschewskya, J., Sakao, T., Lindahl, M.: ProVa - Provider Value Evaluation for Integrated Product Service Offerings, Procedia CIRP 30, pp. 305 - 310, (2015).

8. Mauchand, M., Siadat, A., Perry, N., Bernard, A.: VCS: value chains simulator, a tool for value analysis of manufacturing enterprise processes, Journal of Intellig. Manuf, 23, pp. 1389-1402, (2012).

9. Phumbua, S. and Tjahjono, B.: Towards product-service systems modelling: a quest for dynamic behaviour and model parameters. IJPR, 50(2), pp. 425-442, (2012).

10. Garetti, M., Rosa, P., Terzi, S.: Life cycle Simulation for the design of Product-Service Systems, Computers in Industry, 63, pp. 361-369, (2012).

11. Pezzotta, G., Pinto, R., Pirola, F., Ouertani, M.Z.: Balancing Product-service Provider's Performance and Customer's Value: The SErvice Engineering Methodology (SEEM) Procedia CIRP, Volume 16, pp.50-55, (2014).

12. Alfian, G., Rhee, J., \& Yoon, B.: A simulation tool for prioritizing product-service system models in a carsharing service. Computers \& Industrial Engineering, 70, 59-73 (2014).

13. Erkoyuncu, J. A., Roy, R., Shehab, E., \& Cheruvu, K.: Understanding service uncertainties in industrial PSS cost estimation. IJAMT, 52(9-12), pp. 1223-1238 (2011).

14. Lanza, G., Rühl, J.: Simulation of service costs throughout the life cycle of production facilities. CIRP JMST, 1(4), 247-253 (2009).

15. Durugbo, C., Erkoyuncu, J. A., Tiwari, A., Alcock, J. R., Roy, R., \& Shehab, E.: Data uncertainty assessment and information flow analysis for product-service systems in a library case. IJSOI, 5(4), pp. 330-350, (2010).

16. Wang, X., Durugbo, C.: Analysing network uncertainty for industrial product-service delivery: hybrid fuzzy approach. Expert Systems with Applications, 40(11), pp. 4621-4636, (2013).

17. Boucher, X., Medini, K., Vaillant, H., PS3M: integrative Modelling Environment to support PSS design Procedia CIRP, Volume 73, 2018, pp.73-78, (2018).

18. Medini K.,.Boucher X.: Specifying a modelling language for PSS Engineering - A development method and an operational tool, Computer in industry, Volume 108, Pages 89103, (2019). 
19. Medini, K., Boucher, X., Peillon, S., Vaillant, H., Economic assessment of customer driven value networks for PSS delivery, International Conference on Advances in Production Management Systems, Seoul, Korea, (2018).

20. Murillo-Coba, C., Boucher, X., Medini, M., Gonzalez Feliu, J. : Simulation-based approach to apply uncertainty evaluation framework for PSS economic models, 11th CIRP Conference on Industrial Product-Service Systems, IPS2 2019, May 2019, Zhuhai, China, (2019). 